\title{
Leucocytopenia after rifampicin and ofloxacin therapy in leprosy
}

\author{
P. VIJAYAKUMARAN, N. MANIMOZHI, \\ K. JESUDASAN, S. ARUNTHATHI, MARY JACOB \& \\ P. SAMUEL \\ Schieffelin Leprosy Research \& Training Centre, Karigiri, Tamil- \\ nadu, PIN 632 106, South India
}

Accepted for publication 1 August 1996

\begin{abstract}
Summary New antimycobacterial agents and combined treatment regimens are being introduced for the treatment of leprosy. Ofloxacin is one such broad spectrum antimicrobial agent. In this study rifampicin plus ofloxacin were administered daily for 4 weeks (daily supervised dose). Two patients (and possibly a third patient who refused all investigations) out of 125 patients developed leucocytopenia during the third week of therapy. It was associated with fever, malaise, nausea and loss of appetite. They recovered after cessation of drug treatment. Patients receiving ofloxacin should be monitored for constitutional symptoms suggestive of this complication even though the risk of such complication may be minimal.
\end{abstract}

\section{Introduction}

A large number of leprosy patients have been treated with DDS monotherapy and multidrug therapy (MDT) as recommended by the World Health Organization (WHO). This regimen containing DDS, rifampicin and clofazimine seems to have minimal side-effects. Newer drug regimen ${ }^{1}$ containing newer antimycobacterial drugs ${ }^{2}$ are being tried for treatment of leprosy. Ofloxacin is one of the antimycobacterial agents that is under investigation as an antileprosy $^{2-7}$ drug. When a new drug is employed in treatment, possible adverse reactions need to be monitored carefully. In this paper three case reports of adverse reactions to antileprosy drugs (ofloxacin plus rifampicin) are presented.

At S.L.R. \& T. Centre, Karigiri short-term chemotherapy trial in paucibacillary (PB) leprosy was initiated as part of a randomized double-blind multicentre field trial, sponsored by the World Health Organization (WHO). A total of 125 (previously untreated) PB leprosy patients were included in the study, of whom $44 \%$ were male and $56 \%$ were females. All of them were adults, i.e. age 15 years and above. Of these patients $40.8 \%$ were in the age group of $15-30$ years, $56 \%$ were in $31-45$ years and $3 \cdot 2 \%$ were in $46-65$ years of age.

Baseline investigations done (for all 125) leprosy patients at inclusion in the trial were as follows: 
Blood: total WBC count, differential WBC count, haemoglobin \%.

Blood sugar, urea, liver function tests.

Urine: albumin, sugar \& microscopic examination.

Pregnancy test for all women at inclusion in the trial.

All the patients had normal values before commencement of trial regimen. The study group received daily supervised rifampicin $600 \mathrm{mg}$ and ofloxacin $400 \mathrm{mg}$ for 4 weeks; the control group received WHO-MDT (PB) for 6 months.

The daily dose of rifampicin and ofloxacin was administered by experienced field staff (paramedical worker [leprosy] or non-medical supervisor). All the patients were reviewed by a medical officer once a week during the first 4 weeks of therapy. Apart from this, a patient showing any signs and/or symptoms, e.g. itching, fever, headache, drowsiness, abdominal discomfort, etc. was examined by a medical officer. Hence it was possible to monitor for adverse reactions. Two patients (and possibly a third patient who refused all investigations) were suspected to have developed leucocytopenia. The treatment regimen was decoded and all the three patients were found to have received ofloxacin + rifampicin. All three were females.

\section{Case report 1}

Patient No. 2186 (female/53 years of age) was diagnosed as having borderline-tuberculoid (BT) leprosy. Baseline investigations were done and a trial regimen was administered. On the fourth day of treatment she had a fever for one day which subsided without any treatment. On

Table 1. Laboratory investigations-Patient No. 2186

White blood cell (WBC) counts

\begin{tabular}{|c|c|c|c|c|c|c|c|c|}
\hline \multirow[b]{2}{*}{ Date } & \multirow{2}{*}{$\begin{array}{l}\text { Total WBC count } \\
\mathrm{mm}^{3}\end{array}$} & \multicolumn{5}{|c|}{ Differential count $\%$} & \multirow{2}{*}{$\begin{array}{l}\mathrm{Hb} \\
\mathrm{g} \%\end{array}$} & \multirow{2}{*}{$\begin{array}{c}\mathrm{PCV} \\
\%\end{array}$} \\
\hline & & $\mathrm{N}$ & $\mathrm{E}$ & B & $\mathrm{L}$ & M & & \\
\hline 04.03 .94 & 8300 & 68 & 6 & - & 24 & 2 & $11 \cdot 9$ & - \\
\hline 14.04 .94 & 5600 & 59 & 5 & - & 32 & 4 & - & - \\
\hline 28.04 .94 & 5000 & 62 & 5 & - & 31 & 2 & $11 \cdot 2$ & - \\
\hline 29.04 .94 & 4000 & 56 & 3 & - & 39 & 2 & - & - \\
\hline 02.05 .94 & 6300 & 46 & 4 & - & 46 & 4 & - & - \\
\hline 23.07 .94 & 6000 & 69 & 3 & - & 28 & - & $12 \cdot 1$ & - \\
\hline \multirow[t]{2}{*}{23.11 .94} & 9700 & 64 & 4 & - & 31 & 1 & $11 \cdot 9$ & - \\
\hline & \multicolumn{6}{|c|}{ (on steroid therapy) } & & \\
\hline 28.01 .95 & - & - & - & - & - & - & $13 \cdot 9$ & 35 \\
\hline
\end{tabular}

N, neutrophil; E, eosinophil, B, basophil; L, leucocyte; M, monocyte; PCV, packed-cell volume.

Blood sugar within normal limits.

Liver function tests (LFT)

04.03.94 Albumin-globulin reversal

28.04.94 Globulin level more than alubmin. Serum Alk. Phosphatase \& SGPT

Serum bilirubin

Serum protein (total)

$(39 \mathrm{~g} / \mathrm{Lt} \& 40 \mathrm{~g} / \mathrm{Lt})$

$(30 \mathrm{~g} / \mathrm{Lt} \& 35 \mathrm{~g} / \mathrm{Lt})$

(49.68 \& 48 Units/Lt)

$(3.4 \mu \mathrm{mol} / \mathrm{Lt})$

$(65 \mathrm{~g} / \mathrm{Lt})$ 
the 15th day she had a fever for one day associated with malaise. She was hospitalized and routine investigations (Table 1) were done. The peripheral blood picture revealed that the total WBC count had dropped from 8300 per $\mathrm{mm}^{3}$ to 5600 per $\mathrm{mm}^{3}$. The trial regimen was suspended. The WBC dropped to 4000 per $\mathrm{mm}^{3}$ on the 14 th day after suspension of trial regimen. Further investigations ruled out enteric fever (using the Widal test), malaria and infectious mononucleosis. The constitutional symptoms disappeared within 3 days. Recovery of cell count was noted on the 17th day after suspension of the trial regimen without any specific therapy.

Bone marrow aspiration smears stained by May-Grunwald Giemsa could only be done 10 months after the leucopenic episode (as the patient was not willing to be hospitalized). The smears showed cellular fragments and normoblastic maturation, eosinophilia (7\%), plasmocytosis (6\%), and a slight increase in reticulum cells. A liver function test revealed normal levels of serum bilirubin, serum alkaline phosphatase and SGPT. There was a tendency for albumin and globulin reversal (serum protein) which reverted to normal after cessation of therapy.

This patient had (at inclusion in the study) a large, erythematous, infiltrated patch with an ill-defined margin, dry surface and loss of pain and touch sensation. Her right ulnar nerve was found to be thick without nerve tenderness or neurological deficit. On the 15 th day, i.e. at detection of leucocytopenia, the patch was an ill-defined, hypopigmented macule. Six months later she had an ulnar neuritis (right) which subsided with steroid therapy without residual neurological deficit.

She again had a tingling sensation in the right hand associated with tenderness over the right ulnar nerve 9 months after the leucopenic episode. Surgical decompression of the right ulnar nerve relieved the symptoms.

During the 16th month after the leucopenic episode the patch showed erythema and there was a tingling sensation in the right hand. The right ulnar nerve remained thick but not tender. She was started on WHO-MDT (PB) regimen and steroid therapy.

At the end of MDT (PB) of 6-months duration the patch had become a hypopigmented macule but the ulnar nerve remained thick with a similar tingling sensation recurring frequently. There was no neurological deficit.

\section{Case report 2}

Patient No. 3881 (female/60 years of age) was registered for treatment of BT leprosy. Routine investigations prior to treatment were found to be within normal limits. She had sleeplessness associated with headaches and excessive salivation during the first few days of treatment. During the third week, i.e. 19th day she developed a fever lasting for one day only, and nausea and loss of appetite lasting for 5 days (including 2 days after suspension of the trial regimen). Examination of systems revealed no abnormalities. Routine investigations revealed that there was leucocytopenia. The total WBC count (Table 2) dropped to 2000 per $\mathrm{mm}^{3}$ from 10,000 per $\mathrm{mm}^{3}$. The trial regimen was suspended and the patient was hospitalized. Further investigations ruled out malaria and enteric fever (using the Widal blood test). Recovery of WBC count was noted on the 7th day after suspension of the trial regimen without any specific therapy. The bone marrow aspiration smears of this patient could be done only 11 months after the episode of leucopenia. It showed mild megaloblastic changes and eosinophilia (12\%) (recovering marrow except for hypocellularity). A liver function test (LFT) revealed normal levels of serum bilirubin, serum alkaline phosphatase and SGPT. But 
Table 2. Laboratory investigations-Patient No. 3881

White blood cell (WBC) counts

\begin{tabular}{|c|c|c|c|c|c|c|c|c|}
\hline \multirow[b]{2}{*}{ Date } & \multirow{2}{*}{$\begin{array}{l}\text { Total WBC count } \\
\mathrm{mm}^{3}\end{array}$} & \multicolumn{5}{|c|}{ Differential count $\%$} & \multirow{2}{*}{$\begin{array}{l}\mathrm{Hb} \\
\mathrm{g} \%\end{array}$} & \multirow{2}{*}{$\begin{array}{c}\mathrm{PCV} \\
\%\end{array}$} \\
\hline & & $\mathrm{N}$ & $\mathrm{E}$ & B & $\mathrm{L}$ & $\mathbf{M}$ & & \\
\hline 23.10 .93 & 10000 & 81 & 4 & - & 14 & 1 & $12 \cdot 8$ & 40 \\
\hline 02.01 .94 & 2000 & 56 & 11 & - & 33 & - & 11.9 & - \\
\hline 03.01 .94 & 1600 & 44 & 8 & - & 36 & 12 & - & - \\
\hline 10.01 .94 & 4900 & 40 & 31 & 1 & 27 & 1 & $11 \cdot 6$ & - \\
\hline 17.01 .94 & 8700 & 54 & 29 & - & 16 & 1 & $11 \cdot 6$ & - \\
\hline 26.10 .94 & 9200 & 38 & 40 & - & 21 & 1 & $11 \cdot 6$ & - \\
\hline 22.11 .94 & 10800 & 73 & 14 & - & 10 & 3 & 11.9 & - \\
\hline
\end{tabular}

See Table 1 for notation.

Liver function tests (LFT)

$\begin{array}{lll}23.10 .93 & \text { Albumin : globulin equal } & (45 \mathrm{~g} / \mathrm{L} \& 45 \mathrm{~g} / \mathrm{L}) \\ 28.04 .94 & \text { Globulin more than albumin } & (30 \mathrm{~g} / \mathrm{L} \mathrm{\&} 36 \mathrm{~g} / \mathrm{L}) \\ 22.11 .94 & \text { Albumin : globulin normal } & (42 \mathrm{~g} / \mathrm{L} \& 36 \mathrm{~g} / \mathrm{L}) \\ & \text { Serum alk. phosphatase \& SGPT } & (43 \cdot 2 \& 14 \mathrm{Units} / \mathrm{L}) \\ & \text { Serum bilirubin } & (3 \cdot 4 \mu \mathrm{mol} / \mathrm{L}) \\ \text { Total proteins } & (66 \mathrm{~g} / \mathrm{L}) \\ \text { Glucose } & (6 \cdot 9375 \mu \mathrm{mol} / \mathrm{L})\end{array}$

there was a tendency for albumin and globulin reversal (serum protein). These changes reverted to normal after cessation of therapy.

She had three erythematous infiltrated patches with partly ill-defined margins on the right arm without involvement of the peripheral nerves. At the time of the leucopenic episode the lesions were regressing though active. One month later the lesions became vague hypopigmented macules (inactive). As there was no signs of disease activity she had been on surveillance without antileprosy chemotherapy.

\section{Case report 3}

Patient No. 2185 (female of 30 years age) was started on the trial regimen for BT leprosy

Table 3. Laboratory investigations-Patient No. 2185

White blood cell (WBC) counts

\begin{tabular}{|c|c|c|c|c|c|c|c|c|}
\hline \multirow[b]{2}{*}{ Date } & \multirow{2}{*}{$\begin{array}{c}\text { Total WBC count } \\
\mathrm{mm}^{3}\end{array}$} & \multicolumn{5}{|c|}{ Differential count $\%$} & \multirow{2}{*}{$\begin{array}{l}\mathrm{Hb} \\
\mathrm{g} \%\end{array}$} & \multirow{2}{*}{$\begin{array}{c}\mathrm{PCV} \\
\%\end{array}$} \\
\hline & & $\mathrm{N}$ & $\mathrm{E}$ & B & $\mathrm{L}$ & M & & \\
\hline 07.03 .94 & 10600 & 63 & 13 & 1 & 18 & 5 & $13 \cdot 6$ & - \\
\hline
\end{tabular}

See Table 1 for notation.

Liver function tests (LFT)

07.03.94 Albumin: globulin equal (38g/L \& $34 \mathrm{~g} / \mathrm{L})$ Serum alk. phosphatase \& SGPT levels normal. Serum bilirubin level normal. 
patch on left arm. Results of baseline investigations were within normal limits (Table 3). She had a bitter taste and nausea on the 3rd day of treatment. She was persuaded to continue treatment. The bitter taste persisted associated with loss of appetite and severe abdominal discomfort. It was so disturbing that she refused to continue the treatment on the 19th day. She even refused to undergo investigations. Hence follow-up investigations could not be done. No abnormality was detected on clinical examination. All the symptoms disappeared after termination of therapy. These symptoms were suggestive of drug-induced side-effects similar to the other two patients.

She had three small erythematous infiltrated patches with ill-defined margins and loss of pain and touch sensation. Peripheral nerves were not involved. At the time of the leucopenic episode the lesions were regressing but active.

\section{Discussion}

Rifampicin has been used widely for treatment of leprosy and tuberculosis in various dosage schedules. It is known to cause skin rashes, hepatorenal impairments, haemolytic anaemia, and 'flu' syndrome. ${ }^{8-10}$ When rifampicin was used in combination with thiomide the incidence of hepatitis ${ }^{11,12}$ was reported to be high. Rifampicin has been reported to have interactions ${ }^{8}$ with many other drugs, e.g. oral contraceptives, anticoagulants and antidiabetics.

Fluoroquinolones have minimal side-effects ${ }^{13,14}$ and they are known to cause nausea, vomiting and abdominal discomfort. ${ }^{2,14,15}$ Cases have been reported with symptoms related to the central nervous system. ${ }^{5}$ Ofloxacin has been widely used as a broad spectrum antibacterial agent. ${ }^{16}$ The prescribing information indicates that leucopenia, agranulocytosis, anaemia and thrombocytopenia can occur rarely. Ofloxacin has also been reported as causing leucopenia and eosinophilia which is said to be mild and reversible. ${ }^{17}$

The two patients in this study developed leucopenia during the third week of therapy with a daily dose of ofloxacin and rifampicin. However this seems to be reversible as both these patients recovered completely. These patients with side-effects did not take any other drug or herbal preparations. Viral infections are known to cause leucocytopenia. However no serological test was done to rule out viral infections. Stool examination was not carried out. Serum albumin globulin reversal was observed in two out of the three patients. The significance of this is not clear. Further studies may be required.

There may be two possibilities;

a, ofloxacin might have caused bone marrow depression; and/or

b, rifampicin might have enhanced the side-effect of ofloxacin.

Drug challenge was not attempted as leucocytopenia was considered as a serious complication.

This project was a multicentre randomized double-blind controlled (field-based) clinical trial. From our centre 125 PB leprosy patients were included in the trial. Assuming that 50\% of the study patients received trial regimen containing ofloxacin and rifampicin, then $3 \cdot 2 \%$ of the patients who might have received this regimen had developed leucocytopenia. However it is more appropriate to compute incidence of complications among the total patients included (from all the participating centres) in this multicentre study. There has been no reports of occurrence of leucopenia after ofloxacin therapy and hence it was not possible to provide an estimate of frequency of side-effects. 
Further studies are required on this aspect. However small it may be, one should carefully monitor the patients on ofloxacin therapy to identify any such complications at an early stage to avoid possible serious complications.

\section{Acknowledgment}

This investigation received financial support from the UNDP/World Bank/WHO Special Programme for Research and Training in Tropical Diseases (TDR). We extend our sincere thanks to the World Health Organization for the financial support provided to this project. We are grateful for the commendable support and cooperation from our field staff and hospital staff. We also acknowledge gratefully the expert consultation with Dr Annie Sudarsanam, Professor of Clinical Pathology, CMCH Vellore, South India for reporting on the bone marrow smears. We thank all our leprosy patients for having placed their faith and trust in our hands.

\section{References}

${ }^{1}$ WHO Expert Committee on Leprosy: Sixth report. Technical Report Series 1988 (No. 768): 51 pp.

2 Girdhar BK. Multidrug therapy in leprosy and its future components. Ind J Lepr, 1994; 66(2): 179-208.

${ }^{3}$ Franzblau SG, White KE. Comparative in vitro activities of 20 fluoroquinolones against Mycobacterium leprae. Antimicrob Agents Chemother, 1990 Feb; 34(2): 229-31.

${ }^{4}$ Saito $\mathrm{H}$, Tomioka H, Nagashima K. In vitro and in vivo activities of ofloxacin against Mycobacterium leprae infection induced in mice. Int J Lepr, 1986; 54(4): 560-2.

5 Grosset JH, Guelpa-Lauras CC, Perani EG, Beoletto C. Activity of ofloxacin against Mycobacterium leprae in the mouse. Int J Lepr, 1988; 56(2): 259-264.

${ }^{6}$ Grosset JH, Ji BH, Guelpa-Lauras CC, Perani EG, N'Deli LN. Clinical trial of pefloxacin and ofloxacin in the treatment of lepromatous leprosy. Int J Lepr, 1990; 58(2): 281-95.

7 Tomioka H, Yamada Y, Saito H, Jidoi J. Susceptibilities of Mycobacterium leprae and M. avium complex to the $\mathrm{H}_{2} \mathrm{O}_{2}-\mathrm{Fe}$-mediated halogenation system supplemented with antimicrobial agents. Int J Lepr, 1989; 57(3): 62832.

${ }^{8}$ Chandorkar AG, Burte NP, Gade RK, Bulakh PM. Once monthly rifampicin (1200 mg) plus daily dapsone $(100 \mathrm{mg})$ and clof azimine $(100 \mathrm{mg})$ in the initial treatmnt of lepromatous leprosy. Ind J Lepr, 1984; 56(1): 63-70.

9 Jopling WH. Editorial on Side-effects of antileprosy drugs in common use. Lepr Rev, 1983; 54: 261-270.

${ }_{11}^{10}$ Parking AA, Shah BH. Flu like syndrome with rifampicin pulse therapy. Ind J Lepr, 1989 Apr; 61(2): 209-10.

11 Cartel JL, Millan J, Guelpa-Lauras CC, Grosset JH. Hepatitis in leprosy patients treated by a daily combination of dapsone, rifampicin and a thiomide. Int J Lepr, 1984; 51(4): 461-465.

12 Pattyn SR et al. Hepatotoxicity of the combination of rifampicin-ethionamide in the treatment of leprosy. Int $J$ Lepro, 1984; 52(1): 1-6.

13 Gluckman E, Roudet C, Hirsch I, Devergie A, Bourdeau H, Arlet C, Perol Y. Prophylaxis of bacterial infections after bone marrow transplantation. A randomized prospective study comparing oral broad-spectrum nonabsorbable antibiotics (vancomycin-tobramycin-colistin) to absorbable antibiotics (ofloxacin-amoxicillin). Chemotherapy, 1991; 37 Suppl 1: 33-8.

14 Mary HH, Chandler et al. Multiple dose pharmacokinetics of concurrent oral ciprofloxacin and rifampicin therapy in elderly patients. Antimicrobial Agents Chemotherapy, 1990, pp. 442-47.

15 Michel Drancourt et al. Oral rifampicin plus ofloxacin for treatment of staphylococcus infected orthopedic implants. Antimicrobial Agents Chemotherapy, 1993, 37(6) pp. 1214-218.

16 Murat Akova et al. Quinolones in treatment of human Burcellosis. Comparative trial ofloxacin-rifampin versus doxycycline-rifampin. Antimicrobial Agents Chemotherapy, Sep 1993, 37(9) pp. 1831-834.

17 Wolfson JS. Quinolone antimicrobial agents: adverse effects and bacterial resistance. Eur J Clin Microbiol Infect Dis, 1989; 1081-1091. 